\title{
Intra-acrosomal inhibition of boar acrosin by synthetic proteinase inhibitors
}

\author{
W. Müller-Esterl*, V. Wendt $\uparrow$, W. Leidl $\uparrow$, O. Dann $\ddagger$, E. Shaw \\ G. Wagner 9 and H. Fritz*
}

*Abteilung für Klinische Chemie und Klinische Biochemie in der Chirurgischen Klinik der Universität München, F.R.G.; †Gynäkologische und Ambulatorische Tierklinik der Universität, München, F.R.G., †Institut für Pharmazie und Lebensmittelchemie der Universität, Erlangen, F.R.G.; $\S$ Department of Biology, Brookhaven National Laboratory, Upton, New York 11973, U.S.A.; and ๆSektion Biowissenschaften der Universität, Leipzig, G.D.R.

\begin{abstract}
Summary. Thirteen serine proteinase inhibitors of the guanidine, monoamidine and diamidine type were tested for their ability to inhibit the proteinase acrosin present in the acrosome of ejaculated and capacitated boar spermatozoa. All compounds studied proved to be potent in-vitro inhibitors of acrosin. Inhibition constants $\left(K_{\mathrm{i}}\right)$ in the range of $1.2 \times 10^{-7}$ to $6 \times 10^{-8} \mathrm{M}$ were found for the reversible inhibitors. The intraacrosomal inhibition of acrosin was assessed by the gelatin substrate film method: 2 guanidinobenzoates, one monoamidine and one diamidine derivative proved to inhibit acrosin completely in intact spermatozoa. Intravenous injection of 6-amidino-2-(4amidinophenyl)-indole had no effect on fertilization, but application of 4-nitrophenyl4-guanidinobenzoate in a vaginal suppository gave a $50 \%$ reduction of fertilization.
\end{abstract}

\section{Introduction}

Acrosin is a trypsin-like enzyme associated with the acrosome of vertebrate spermatozoa (McRorie $\&$ Williams, 1974). The proteinase is supposed to effect the lysis of the innermost glycoprotein layers of the oocyte at the time of sperm penetration through the zona pellucida (Stambaugh \& Buckley, 1968). Zona penetration and subsequent fertilization is effectively prevented in the presence of acrosin-directed inhibitors, e.g. the pancreatic trypsin inhibitor (Zaneveld, Robertson, Kessler \& Williams, 1970a) and $\mathrm{N}^{\alpha}$-tosyl-L-lysyl-chloromethane (Zaneveld, Robertson \& Williams, 1970b). Consequently, concepts of anti-enzymic contraception have been developed, and a series of acrosin inhibitors has been tested for their potential antifertility efficacy (Schill, Feifel, Fritz \& Hammerstein, 1981).

A convenient tool to assess the proteolytic activity of individual spermatozoa is provided by the gelatin substrate film method originally developed by Gaddum \& Blandau (1970) and adapted to inhibitor studies by Wendt, Leidl \& Fritz (1975a, b). Briefly, incubation of spermatozoa on a gelatin film results in disintegration of the acrosome thus leading to a circular digestion zone around the sperm head. Two lines of evidence suggest that proteolysis of the gelatin matrix is caused by acrosin liberated from leaky acrosomes. First, the mean lysis area and the mean content of acrosin was found to be well correlated for different sperm populations (Wendt et al., 1975a). Second, gelatin digestion was completely prevented when acrosin-specific inhibitors were present in the substrate film (Wendt et al., 1975a). Hence, the gelatin film method permits a semiquantitative estimation of the inherent proteolytic activity of single spermatozoa. 
The present communication examines the inhibition of boar sperm acrosin by synthetic inhibitors of the guanidine, monoamidine, and diamidine type in vitro and in vivo.

\section{Materials and Methods}

Trishydroxymethylaminomethane (Tris), citric acid, and fructose were products from E. Merck, Darmstadt, F.R.G. Kodak autoradiographic stripping plates AR 10 were obtained from Kodak, Stuttgart, F.R.G. Acrosin (EC 3.4.21.10) was purified from boar spermatozoa as described by Müller-Esterl \& Fritz (1981).

\section{Inhibitors}

The compound number is given in parentheses.

Guanidines. (1) Ethyl-4-guanidinobenzoate (Mares-Guia \& Shaw, 1967); (2) phenyl-4-guanidinobenzoate (PPGB) (Markwardt, Drawert \& Walsmann, 1974); (3) 4-nitrophenyl-4-guanidinobenzoate (NPGB) (Chase \& Shaw, 1970).

Diamidines. (4) 1,2-Bis-(5-amidino-2-benzofuranoyl)ethylene (Tidwell et al., 1978); (5) 2-[4-(4amidinophenoxy)phenyl]-6-indolylcarboxamidine (Tidwell et al., 1978); (6) 6-amidino-2-(4amidinophenyl)-3-aminoindole (Tidwell et al., 1978); (7) 5-amidino-2-(4-amidinophenyl)benzofuran (Tidwell et al., 1978); (8) 6-amidino-2-(4-amidinophenyl)thionaphthene (Tidwell et al., 1978); (9) 6-amidino-2-(4-amidinophenyl)indole (AAPI) (Tidwell et al., 1978).

Monoamidines. (10) Ethyl-4-amidinophenylpyruvate (Markwardt et al., 1974); (11) 4amidinophenylpyruvic acid (Markwardt et al., 1974); (12) 4-amidinophenyl-4-methoxybenzoate (APMB) (Markwardt et al., 1974).

Phenylmethanesulphonates. (13) Nitrophenyl-4-isothiouroniummethylphenylmethanesulphonate (Wong, Green \& Shaw, 1978).

\section{Inhibition constants}

Inhibition constants were determined according to Dixon (1972), using purified boar acrosin, and the assay system of Schleuning \& Fritz (1975). Duplicates of experiments were performed for 5 different concentrations of each inhibitor ranging from $1.9 \times 10^{-8} \mathrm{M}$ to $5.7 \times 10^{-7} \mathrm{M}$.

\section{Preparation of spermatozoa}

Semen was collected from healthy boars (Deutsches Veredeltes Landschwein) by an artificial vagina. One part of the semen (referred to as ejaculated spermatozoa) was processed immediately after ejaculation (see below), and another part $(50 \mathrm{ml})$ was used to inseminate sows (Göttinger Minipig) 1 day after onset of oestrus. At $6 \mathrm{~h}$ after artificial insemination the spermatozoa were recovered from the genital tract by hysterectomy and flushing of the uterus and oviducts (uterine spermatozoa). Ejaculated and uterine spermatozoa were suspended in the diluting buffer ( $300 \mathrm{~mm}$ Tris, $100 \mathrm{~mm}$-citric acid, $82 \mathrm{~mm}$-fructose, $\mathrm{pH} \mathrm{6.9)}$ and the suspension centrifuged (10 $\mathrm{min}, 600 \mathrm{~g}$, $25^{\circ} \mathrm{C}$ ). The supernatant was decanted and the sperm pellet was resuspended in an appropriate volume of diluting buffer to give a final sperm count of $10^{5} \mathrm{spermatozoa} / \mathrm{ml}$.

\section{Incubation of spermatozoa}

To $1 \mathrm{ml}$ of the sperm suspension $1 \mathrm{ml}$ of freshly prepared inhibitor solution was added to give a final concentration of $1 \mathrm{mM}$. The suspension was incubated $\left(15 \mathrm{~min}, 37^{\circ} \mathrm{C}\right)$, centrifuged $(10 \mathrm{~min}$, $600 \mathrm{~g}, 25^{\circ} \mathrm{C}$ ), and the supernatant decanted. The sediment was washed with $10 \mathrm{ml}$ diluting buffer to 
remove excess inhibitor not associated with spermatozoa. The resulting suspension was centrifuged $\left(15 \mathrm{~min}, 600 \mathrm{~g}, 25^{\circ} \mathrm{C}\right.$ ), the supernatant was removed and the sediment resuspended in $1 \mathrm{ml}$ diluting buffer. An aliquant $(150 \mu \mathrm{l})$ was transferred to a gelatin film and further processed.

\section{Gelatin lysis}

The gelatin film technique was essentially performed as described earlier (Wendt $e t$ al., 1975a). Briefly, $1.5 \times 10^{4}$ spermatozoa were applied on the preswollen gelatin film and distributed over the surface of the film by a glass rod. Triplicates were assayed for each inhibitor. The samples were incubated $\left(30 \mathrm{~min}, 37^{\circ} \mathrm{C}\right)$ and air-dried to stop gelatin digestion. The mean lysis area of 150 spermatozoa was assessed under a microscope equipped with an ocular micrometer. Inhibitor-free incubates served as standards. The percentage of proteolytic ('gelatinolytic') spermatozoa and the progressive motility of the sperm cells were routinely checked to monitor the non-specific cytotoxic effects of the inhibitors.

\section{Treatment with inhibitors in vivo}

Intravaginal. Compound $3(10 \mathrm{mg})$ was suspended in $1 \mathrm{ml}$ suppository basis (oleum cacao) and the resultant suppository was deposited in the anterior part of the vagina of rabbits before artificial insemination. Two control groups without suppositories and suppositories without inhibitor were also used. The does were killed 6 days after insemination and the number of blastocysts present in the genital tract was determined.

Systemic. Compound $9(40 \mathrm{mg})$ was dissolved in $1 \mathrm{ml} 0.15 \mathrm{M}-\mathrm{NaCl}$ and injected intravenously to female rabbits pretreated with 100 PMSG i.u. and 60 i.u. hCG. The does were then artificially inseminated $\left(5 \times 10^{6}\right.$ spermatozoa each). Untreated rabbits served as the control group. The animals were killed $12 \mathrm{~h}$ after insemination and ova were recovered from the genital tract. The total number of ova which had undergone cleavage and the total number of spermatozoa found in the zona pellucida were determined.

\section{Results}

\section{Inhibition constants}

Two classes of inhibitors with respect to their mode of action were used: irreversible inhibitors (Compounds 1, 2, 3,12 and 13) which form a covalent bond to the active site of the enzyme, and reversible inhibitors (Compounds 4, 5, 6, 7, 8, 9, 10 and 11) which form a non-covalent complex with acrosin. The inhibition constants $\left(K_{\mathrm{i}}\right)$ of the reversible inhibitors were $1.2 \times 10^{-7}, 1.6 \times 10^{-7}$, $1.5 \times 10^{-7}, 6.4 \times 10^{-7}, 6 \times 10^{-8}, 1.3 \times 10^{-7}, 7.5 \times 10^{-7}$ and $1.7 \times 10^{-7} \mathrm{M}$ for Compounds 4, 5, 6, $7,8,9,10$ and 11 respectively. These values indicate that these compounds are strong acrosin inhibitors in vitro.

\section{Gelatin film lysis}

The digestion halos on gelatin film (P1. 1, Figs $1 \&$ 2), were examined and mean lysis areas were assessed. As shown in Table 1, guanidines proved to be the strongest inhibitors under the conditions of the experiment. Compounds 2 and 3 completely prevented halo formation by ejaculated spermatozoa and Compound 1 induced a $71 \%$ reduction compared to the control. Compound 2 was only effective in concentrations of $1 \mathrm{~mm}$ but Compound 3 inhibited completely at the $0 \cdot 1 \mathrm{~mm}$ level.

Of six diamidines tested, Compound 9 exerted the most pronounced inhibitory effect. 
Compounds 7 and 8 were less effective ( 79 and $69 \%$ inhibition, respectively) while Compounds 4,5 and 6 had little effect.

Compound 12 was the most powerful monoamidine inhibitor (Table 1). Compound 11 was a strong inhibitor $(61 \%)$ but only moderate inhibition $(25 \%)$ was shown by Compounds 10 and 13.

Halo formation of uterine ('capacitated') spermatozoa was similarly affected by the inhibitors applied. Strong inhibitors of gelatin lysis by ejaculated spermatozoa were also strong inhibitors of gelatin lysis by uterine spermatozoa and vice versa (see Table 1). However, for some compounds (e.g. 4, 5, 10 and 11) uterine spermatozoa were more susceptible to inhibition than were ejaculated spermatozoa, but this was not a general feature (see Compounds 6,7 and 8).

Generally, the progressive motility of spermatozoa was affected by inhibitor treatment (Table 1). However, no correlation was found between reduction of progressive motility and inhibition of sperm proteolytic activity.

Table 1. Mean lysis areas caused by ejaculated and uterine spermatozoa following incubation with $1 \mathrm{~mm}$ inhibitor

\begin{tabular}{|c|c|c|c|c|c|c|c|c|}
\hline \multirow[b]{2}{*}{ Compound } & \multicolumn{3}{|c|}{ Ejaculated spermatozoa } & \multirow{2}{*}{$\begin{array}{c}\text { Sperm with } \\
\text { progressive } \\
\text { motility } \ddagger \\
(\%)\end{array}$} & \multicolumn{3}{|c|}{ Uterine spermatozoa } & \multirow{2}{*}{$\begin{array}{c}\text { Sperm with } \\
\text { progressive } \\
\text { motility } \\
(\%)\end{array}$} \\
\hline & $\begin{array}{l}\text { Lysis area } \\
\left(\mu \mathrm{m}^{2}\right)^{*}\end{array}$ & $\begin{array}{c}\text { Inhibition } \\
(\%)\end{array}$ & $\begin{array}{c}\text { Active sperm. } \dagger \\
(\%)\end{array}$ & & $\begin{array}{c}\text { Lysis area } \\
\left(\mu \mathrm{m}^{2}\right)^{*}\end{array}$ & $\begin{array}{c}\text { Inhibition } \\
(\%)\end{array}$ & $\begin{array}{c}\text { Active sperm. } \dagger \\
(\%)\end{array}$ & \\
\hline 1 & $164 \pm 63$ & 71 & 75 & 50 & $154 \pm 67$ & 84 & 40 & 40 \\
\hline 2 & $<10$ & $>98$ & 40 & 40 & $<10$ & $>98$ & 0 & 10 \\
\hline $3 \S$ & $<10$ & $>98$ & 77 & 30 & $<10$ & $>98$ & 38 & 10 \\
\hline 4 & $797 \pm 445$ & 0 & 85 & 30 & $569 \pm 244$ & 30 & 33 & 20 \\
\hline 5 & $587 \pm 241$ & 5 & 73 & 35 & $601 \pm 334$ & 34 & 27 & 20 \\
\hline 6 & $427 \pm 76$ & 10 & 80 & 60 & $1069 \pm 349$ & $\mathbf{0}$ & 70 & 40 \\
\hline 7 & $193 \pm 116$ & 69 & 54 & 50 & $402 \pm 172$ & 56 & 21 & 30 \\
\hline 8 & $131 \pm 151$ & 79 & 94 & 60 & $239 \pm 110$ & 73 & 19 & 10 \\
\hline 9 & $<10$ & $>98$ & 91 & 50 & $<10$ & $>98$ & 0 & 40 \\
\hline 10 & $342 \pm 81$ & 28 & 85 & 50 & $<10$ & $>98$ & 71 & 10 \\
\hline 11 & $185 \pm 81$ & 61 & 91 & 70 & $151 \pm 32$ & 83 & 61 & 20 \\
\hline 12 & $<10$ & $>98$ & 80 & 60 & $<10$ & $>99$ & 0 & 10 \\
\hline 13 & $133 \pm 39$ & 23 & 51 & 30 & $106 \pm 28$ & 26 & 11 & 0 \\
\hline
\end{tabular}

* Values are mean \pm s.e.m. for 150 spermatozoa.

$\uparrow 300$ spermatozoa tested for gelatinolytic activity.

$\$ 82 \%$ spermatozoa with progressive motility in an untreated control.

$\S$ Final concentration in the incubation buffer $0.1 \mathrm{mM}$.

I $55 \%$ spermatozoa with progressive motility in an untreated control.

In-vivo experiments

Compound 3. As shown in Table 2, intravaginal application of Compound 3 resulted in a $50 \%$ reduction of fertilization.

Compound 9. Intravenous administration of Compound 9 did not impair fertilization (Table 3).

Table 2. Intravaginal application of an acrosin inhibitor (Compound 3) and fertilization rates in rabbits 6 days after insemination

\begin{tabular}{lccc}
\hline \multicolumn{1}{c}{ Treatment } & $\begin{array}{c}\text { No. of } \\
\text { rabbits }\end{array}$ & $\begin{array}{c}\text { Mean } \pm \text { s.e.m. } \\
\text { no. of blastocysts }\end{array}$ & $\begin{array}{c}\text { No. of rabbits } \\
\text { pregnant (\%) }\end{array}$ \\
\hline None (no suppository) & 7 & $6 \cdot 3 \pm 5 \cdot 3$ & $7(100)$ \\
Vaginal suppository without inhibitor & 9 & $17 \cdot 7 \pm 15 \cdot 0$ & $9(100)$ \\
Vaginal suppository with 10 mg Compound 3/ml & 10 & $10 \cdot 4 \pm 4 \cdot 4$ & $5(50)$ \\
\hline
\end{tabular}


PLATE 1
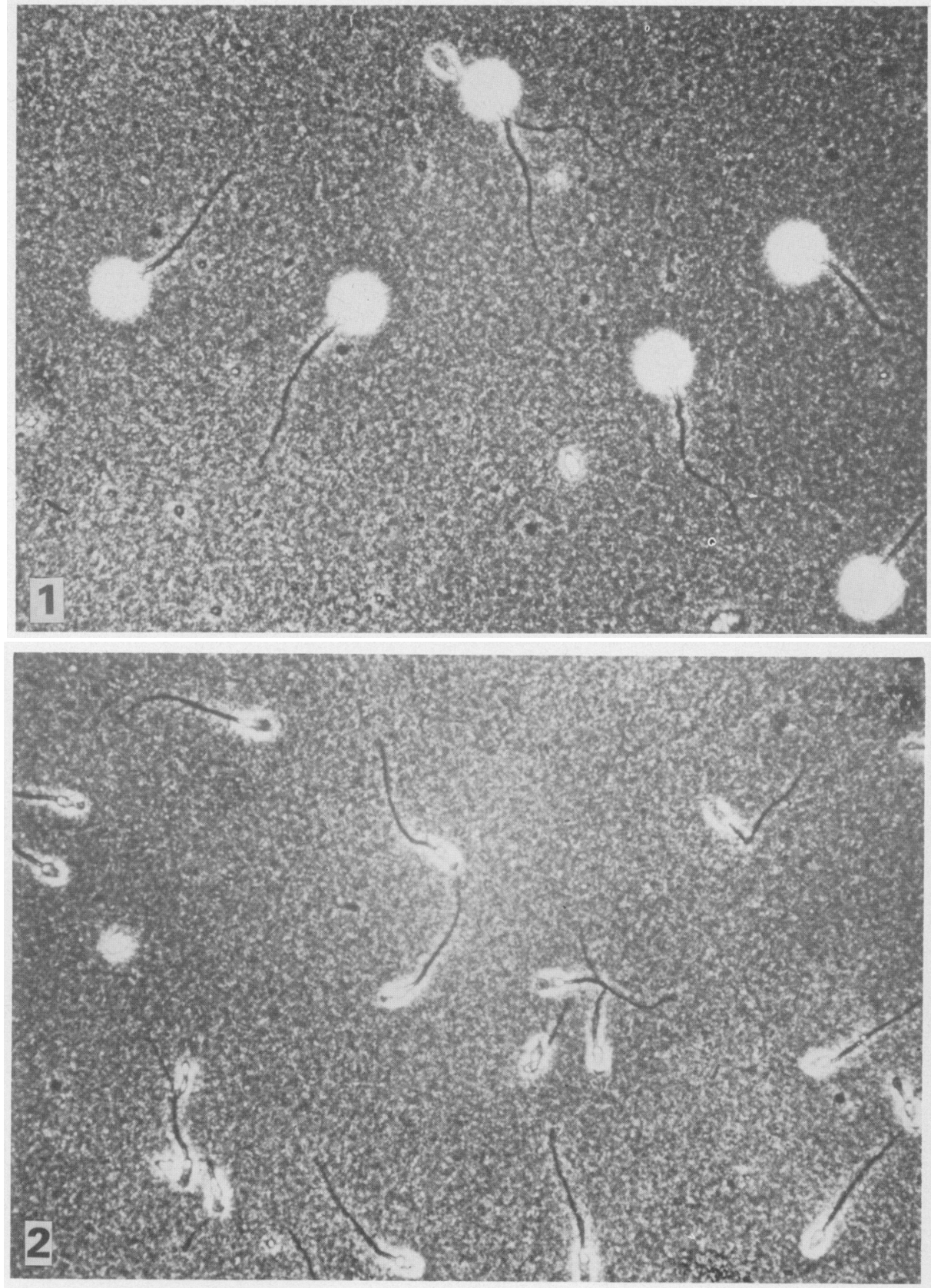

Fig. 1. Gelatin lysis of ejaculated boar spermatozoa. After removal of the seminal plasma the spermatozoa were incubated on a $10 \mu \mathrm{m}$ gelatin film for $30 \mathrm{~min}$ at $37^{\circ} \mathrm{C}$ (see 'Methods'). Liberation of acrosin from disintegrating sperm acrosomes leads to a visible concentric digestion zone ("halo') around the sperm head. $\times 400$.

Fig. 2. Inhibition of gelatin lysis of ejaculated spermatozoa pretreated with an acrosin inhibitor. The spermatozoa were incubated with $0 \cdot 1 \mathrm{~mm}$-Compound 3 , then thoroughly washed with inhibitor-free buffer and incubated on a gelatin film (for details, see 'Methods'). Halo formation is completely prevented. $\times 400$. 
Table 3. Intravenous application of an acrosin inhibitor (Compound 9) and fertilization in rabbits

\begin{tabular}{lcccccc}
\hline \multicolumn{1}{c}{ Treatment } & $\begin{array}{c}\text { No. of } \\
\text { rabbits }\end{array}$ & $\begin{array}{c}\text { No. of } \\
\text { ovulations }\end{array}$ & $\begin{array}{c}\text { No. of ova } \\
\text { recovered }\end{array}$ & $\begin{array}{c}\text { No. of ova } \\
\text { cleaved }\end{array}$ & $\begin{array}{c}\text { No. of spermatozoa } \\
\text { fertilization }\end{array}$ & $\begin{array}{c}\text { inside the zona } \\
\text { pellucida }\end{array}$ \\
\hline $\begin{array}{l}\text { Control }(1 \mathrm{ml} 0 \cdot 15 \mathrm{M}-\mathrm{NaCl}) \\
\text { Compound } 9(40 \mathrm{mg} \mathrm{in} 1 \mathrm{ml} \\
0.15 \mathrm{M}-\mathrm{NaCl})\end{array}$ & 5 & $37 \cdot 0 \pm 28 \cdot 3$ & $34 \cdot 8 \pm 26 \cdot 2$ & $23 \cdot 6 \pm 21 \cdot 1$ & $67 \cdot 8$ & $9 \cdot 9 \pm 8 \cdot 7$ \\
\hline
\end{tabular}

Values are mean \pm s.e.m.

\section{Discussion}

Inhibition of the sperm proteinase acrosin has been suggested as a promising new approach to contraception (Joyce, Freund \& Peterson, 1979). Acrosin represents the major proteinase of vertebrate spermatozoa with an intra-acrosomal concentration of $1.6 \mathrm{~mm}$ (corresponding to $64 \mathrm{mg}$ acrosin/ml acrosomal plasma) (Müller-Esterl \& Fritz, 1981). The acrosome of intact spermatozoa contains the inactive precursor of acrosin (proacrosin) which is autocatalytically converted to the active enzyme at the time of the acrosome reaction (Green, 1978; Harrison \& Brown, 1979). Moreover, minor acrosomal proteinases other than acrosin have been reported (Morton, 1977). Consequently, inhibition of gelatin lysis may be interpreted as (i) inhibition of the proacrosinacrosin conversion, (ii) inhibition of activated acrosin, and (iii) inhibition of proteinases other than acrosin.

The gelatin substrate film used in this study does not discriminate between these mechanisms as gelatin lysis is a phenomenon related to the net output of proteolytic spermatozoa from disintegrating spermatozoa. However, both inhibition of the autocatalytic proenzyme activation by acrosin and inhibition of the fully activated enzyme necessitates acrosin-directed inhibitors regardless of the actual state of the proacrosin-acrosin system. At present we cannot exclude the possibility that proteinases other than acrosin, which are not inhibited by acrosin-directed inhibitors, are involved in the expression of sperm proteolytic activity. Unfortunately, these sperm proteinases are only poorly characterized so far, and conclusive evidence for their participation in proacrosin-acrosin conversion has not yet been presented.

It has been suggested that acrosin inhibitors must traverse the outer acrosomal membranes to reach their target enzyme (Schill et al., 1981). Restriction of transmembrane diffusion of acrosin inhibitors would lead to an incomplete inactivation of intra-acrosomal acrosin due to the low final concentration of the inhibitor in the acrosome. Factors critical to transmembrane diffusion are structural features such as size, charge, bulkiness and hydrophobicity, and the transmembrane concentration gradient of the inhibitors. From our present results, only limited structure-function relationships can be deduced as the number of inhibitors studied is too small. Generally, low molecular weight inhibitors performed more effectively than did the high molecular weight inhibitors, as demonstrated for human spermatozoa (Schill et al., 1981). The irreversible inhibitors seemed to be superior to reversible inhibitors. This functional difference of the inhibitor action could explain the different molar quantities required for complete intra-acrosomal inhibition of acrosin by Compound 3, an irreversible inhibitor $(0.1 \mathrm{~mm})$ and Compound 9 , a reversible inhibitor ( $\mathrm{mm}$ ). Even minor structural variations of the inhibitor may result in a significant change in inhibitory potency. For example, Compound 6, which differs from Compound 9 only by an additional amino group, caused $10 \%$ inhibition compared to the $95 \%$ inhibition by the unsubstituted compound.

Restriction of transmembrane diffusion was found to be more pronounced in human spermatozoa (Schill et al., 1981): of 19 synthetic low molecular weight inhibitors tested only NPGB (Compound 3) proved to be a potent inhibitor of intra-acrosomal acrosin. Hence, species-specific differences in the membrane permeability of spermatozoa may exist. 
Mechanisms other than transmembrane diffusion should also be taken into account to explain the observed effects. Adsorption of the inhibitors to the outer surface of the acrosomal membranes, leading to inhibition of acrosin subsequent to its leakage from the disintegrating acrosome, would be another possibility. Such a mechanism provides a rationale for the observed inhibition of gelatin lysis when spermatozoa are pretreated with high molecular weight inhibitors such as aprotinin (Schill et al., 1981) or seminal plasma inhibitor (Wendt et al., 1975b). Moreover, partial reduction of halo formation may be interpreted in terms of displacement of reversible inhibitors by the substrate gelatin.

Systemic application of acrosin inhibitors failed to impair fertilization. However, preliminary results on the intravaginal application of NPGB indicate a moderate reduction of fertilization. Due to the toxicity of this inhibitor only small amounts of NPGB were applied, and the mode of application has not yet been modified.

This work was supported by the U.S. Department of Energy (E.S.) and the Deutsche Forschungsgemeinschaft (W.M.E.).

\section{References}

Chase, T. \& Shaw, E. (1970) Titration of trypsin, plasmin, and thrombin with p-nitrophenyl-p'-guanidinobenzoate $\cdot \mathrm{HCl}$. Methods Enzymol. 19, 20-27.

Dixon, M. (1972) The graphical determination of $\mathbf{K}_{\mathrm{m}}$ and $\mathrm{K}_{\mathrm{i}}$. Biochem. J. 129, 197-202.

Gaddum, P. \& Blandau, R.J. (1970) Proteolytic reaction of mammalian spermatozoa on gelatin membranes. Science, N.Y. 170, 749-751.

Green, D.P.L. (1978) The activation of proteolysis in the acrosome reaction of guinea-pig sperm. J. Cell Sci. 32, 153-164.

Harrison, R.A.P. \& Brown, C.R. (1979) The zymogen form of acrosin in testicular, epididymal, and ejaculated spermatozoa. Gamete Res. 2, 75-87.

Joyce, C., Freund, M. \& Peterson, R.N. (1979) Contraceptive effects of intravaginal application of acrosin and hyaluronidase inhibitors in rabbit. Contraception 19, 95-105.

Mares-Guia, M. \& Shaw, E. (1967) The specific inactivation of trypsin by ethyl-p-guanidinobenzoate. J. biol. Chem. 242, 5782-5788.

Markwardt, F., Drawert, J. \& Walsmann, P. (1974) Synthetic low molecular weight inhibitors of serum kallikrein. Biochem. Pharmacol. 23, 2247-2256.

McRorie, R.A. \& Williams, W.L. (1974) Biochemistry of mammalian fertilization. Ann. Rev. Biochem. 43, 777803.

Morton, D.B. (1977) Lysosomal enzymes in mammalian spermatozoa. In Proteinases in Mammalian Cells and Tissues, pp. 445-500. Ed. A. J. Barrett. North Holland Publishing, Co., Amsterdam.

Müller-Esterl, W. \& Fritz, H. (1981) Sperm acrosin. Methods Enzymol. 80, 621-632.
Schill, w.B., Feifel, M., Fritz, H. \& Hammerstein, J. (1981) Inhibitors of acrosomal proteinase as antifertility agents: a problem of acrosomal membrane permeability. Int. J. Androl. 4, 25-38.

Schleuning, W.D. \& Fritz, H. (1975) Sperm acrosin. Methods Enzymol. 45, 330-342.

Stambaugh, R. \& Buckley, J. (1968) Zona pellucida dissolution enzymes of the rabbit sperm head. Science, N.Y. 161, 585-586.

Tidwell, R.R., Geratz, J.D., Dann, O., Volz, G., Zeh, D. \& Loewe, H. (1978) Diarylamidine derivatives with one or both of aryl moieties consisting of an indole or indole-like ring. Inhibitors of arginine-specific esteroproteases. J. med. Chem. 21, 613-623.

Wendt, V., Leidl, W. \& Fritz, H. (1975a) The lysis effect of bull spermatozoa on gelatin substrate film. HoppeSeyler's Z. Physiol. Chem. 356, 315-323.

Wendt, V., Leidl, W. \& Fritz, H. (1975b) Influence of various proteinase inhibitors on the gelatinolytic effect of ejaculated and uterine boar spermatozoa. Hoppe-Seyler's Z. Physiol. Chem. 356, 1073-1078.

Wong, S.C., Green, G.D.J. \& Shaw, E. (1978) Inactivation of trypsin-like proteases by sulfonylation. J. med. Chem. 21, $456-459$.

Zaneveld, L.J.D., Robertson, R.T., Kessler, M. \& Williams, W.L. (1970a) Inhibition of fertilization in vivo by pancreatic and seminal plasma trypsin inhibitor. J. Reprod. Fert. 25, 387-392.

Zaneveld, L.J.D., Robertson, R.T. \& Williams, W.L. (1970b) Synthetic enzyme inhibitors as antifertility agents. FEBS Lett. 11, 345-347.

Received 29 January 1982 